\title{
Evaluation of views and perceptions of the medical faculty students about distance anatomy education during the COVID-19 pandemic
}

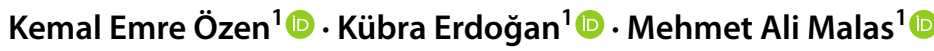 \\ Received: 19 August 2021 / Accepted: 29 November 2021 / Published online: 10 January 2022 \\ (c) The Author(s), under exclusive licence to Springer-Verlag France SAS, part of Springer Nature 2021
}

\begin{abstract}
Purpose This study aimed to investigate the students' opinions about the distance anatomy education given in our faculty at the COVID-19 pandemic and present our department's experiences.

Methods An online questionnaire designed for medical faculty students. The questionnaire was applied to 355 volunteer medical faculty students. The questionnaire consisted of demographics, five-point Likert items, and open-ended questions. The questionnaire was applied between August and September 2020. Distance anatomy education activities were evaluated during March and July 2020.

Results Results showed face-to-face theoretical anatomy education was found to be more effective than distance anatomy education conducted with recorded lecture videos. Even though the positive aspects of distance anatomy education stand out in topics, such as time management, it has been stated that cadaver and laboratory education has been disrupted. Most of the students agreed that they spent more time on supplementary resources during distance anatomy education.

Conclusion The COVID-19 pandemic has provided an unexpected experimental environment. The demand for a blended method, which consists of distance (supported by video recordings) theoretical anatomy education and face-to-face practical anatomy education for the post-pandemic period comes to the fore. Distance anatomy education brings some problems with it due to its nature, and it is essential to seek unique solutions to them. Evaluating the perceptions of the parties will play an essential role in solving the problems of distance anatomy education and in the formation of future anatomy education styles.
\end{abstract}

Keywords Questionnaire · Survey · COVID-19 · Pandemic · Distance Anatomy Education · Distant Anatomy Education, Distance Education, Medical Faculty · Gross Anatomy Education · Medical Education · Coronavirus · Online Anatomy

Education $\cdot$ Remote teaching

\section{Introduction}

The COVID-19 pandemic caused by a new type of coronavirus [Severe Acute Respiratory Syndrome Coronavirus 2 SARS-CoV-2)] was declared a global "COVID-19 pandemic" on March 11, 2020, by the world health organization

Kemal Emre Özen

kemalemre9870@yahoo.com; kemalemre.ozen@ikcu.edu.tr

Kübra Erdoğan

erdkubra@yahoo.com

Mehmet Ali Malas

mehmetalimalas@gmail.com

1 Department of Anatomy, Faculty of Medicine, İzmir Kâtip Çelebi University, İKÇÜ Çiğli Ana Yerleşkesi, Balatçık Mah., Havaalanı Şosesi Cad., Nu: 33/2 35620 Çiğli, İzmir, Turkey
$[15,18,33]$. The COVID-19 pandemic introduced the world to a new and compulsive process, not only in health but also in the fields of sociology, economy, education, and even the ecology. Similar situations were experienced in the influenza pandemic, which was encountered earlier in world history in 1918, and distance education experiences were obtained through correspondence [28]. Although the SARS epidemic in 2003 created a new experience in medical education, its worldwide results were more limited than the impact of the COVID-19 pandemic on education and medical education [23, 26].

The first case of COVID-19 in our country was reported on March 11, 2020 [34]. Thus, higher education institutions countrywide decided to conduct undergraduate and graduate education in the second term of the 2019-2020 academic year, not face-to-face but with distance education methods, and it was immediately put into practice. Although its impact 
on health education is clear, the online teaching model was suddenly and highly integrated into medical education and quickly adapted. In this process, the COVID-19 pandemic has created new experiences for medical educators. Educators who had no previous experience in distance education, who would not probably believe and prefer this method, and who would probably have difficulty adopting a distance education method had to adapt to distance education more quickly than they expected [25]. However, the search for online education alternatives in medical education started before the COVID-19 pandemic [10]. Anatomy education was given through distance education in our country in the early period of the COVID-19 pandemic, the same as in the world. Theoretical lessons were highly conducted on digital platforms. In terms of practical lessons and exams, decisions were made by the institutions evaluating conditions, such as the number of students, physical and digital feasibility of the institution, the current and instant progress of the pandemic throughout the country $[4,31]$.

Receiving quick feedback based on opinions and perceptions from the people involved in this early period, and controlling or improving the education process accordingly to these opinions can be counted among the first reactions to the pandemic [27, 35]. Exploring the perceptions and views of students and educators using feedback mechanisms can be the first opportunity to see the impact of acute reactions and to manage the adaptation process. In the initial period of the COVID-19 pandemic, there was not enough and detailed data, including educational practices from previous pandemic periods in the literature, to guide medical educators in this area.

Contributions to the literature in the early period after the emergence of the COVID-19 pandemic mainly consist of comments from faculty members, letters to the editor, and announcing the general reactions of the universities of the countries $[1,9,11,17,24]$.

How educators and students perceive the educational process provides valuable information for the evaluation and development of the process [3, 7, 27, 35]. For this reason, studies in which the views of larger masses are taken with methods such as surveys for comprehensive evaluations seem few. Research is needed to examine student perception and experiences in distance education in this process. It is seen that the literature about anatomy education is so limited. It is difficult to produce solutions using previous experiences of anatomy education problems in this process. In this sense, it seems essential to record today's problems, solutions, and experiences.

In some previous studies, students' opinions were taken about certain aspects of distance anatomy education $[2,7$, $8,14,16,20,27,35]$. However, it was observed that some opinions were not received from participants, such as about blended education, and open-ended questions were not adequately evaluated analytically in these studies.

The COVID-19 pandemic has created a highly realistic experimental environment for the distance education of anatomy in medical education. Distance anatomy education given in this environment was determined as the subject of this study. This research aimed to evaluate the anatomy education we provided under pandemic conditions from students' perspective, obtain data for revision of our anatomy education, present our department's experience on distance education, and understand the effects of the COVID-19 pandemic on distance anatomy education.

\section{Materials and methods}

This research was carried out as a survey (questionnaire) study on 355 (191 female, 164 male) volunteer students who were replied to an online call and educated in medical school as the term-1 (first-year students) and term-2 (second-year students) in the 2019-2020 academic year. An approval was obtained from the institutional ethics committee for the study (No: 756/18.06.2020).

Our educational program of the medical faculty is nationally accredited by the "Association for Evaluation and Accreditation of Medical Education Programs" (http:// tepdad.org.tr/en). In our medical faculty, anatomy education is given to students in the first 2 years. Introduction to anatomy, terminology, and locomotor system (osteology, arthrology, myology) lessons are given in the first year and anatomy of the organs in the second year. With the onset of the COVID-19 pandemic, the university and faculty administration decided to continue basic medical science education with the distance education model in accordance with national precautions simultaneously. In this process, our department continued to share course materials, educational resources archive (texts, PowerPoint presentations, video recordings of the lectures) with students using distance education methods.

Using our university's existing institutional learning management system (LMS), theoretical and practical lectures can be given synchronously and asynchronously according to the distance education module which is designed after the COVID-19 pandemic started. Synchronous lectures were conducted through online live meetings. Lecturers and students met at the date and time published in the curriculum. Lecturer shared the computer screen and camera image with the students. The lectures could be recorded, and students could access them after the live meeting. Asynchronous lectures were the videos which can be recorded through the LMS and shared with the students via the LMS. At the onset of the pandemic, arthrology and myology lectures were given to the first-year students. Digestive and urogenital 
systems lectures were given to the second-year students via distance education in our department. In this process, students were encouraged to ask their questions on lectures through the tools, such as e-mail and the LMS message system, and these questions were answered by the faculty members. Anatomy theoretical lectures were conducted both in synchronous and asynchronous way. Face-to-face model and cadaver sessions in anatomy laboratory between March and July 2020 have been canceled due to a large number of students. However, planning make-up classes were discussed with the faculty administration after returning to face-to-face education, due to the conditions of the COVID-19 pandemic. During the pandemic, face to face anatomy practice/laboratory courses were not carried out in the anatomy laboratory. Instead, the recommended online resources were used as practical educational materials for anatomy practical courses by students. Without considering this point of view of the questionnaire, one may think that as if there was a contradiction between the questions 9,10 and 11 . However, there would not be a contradiction for the survey participants, because the participants answered the questions according to what they lived. Therefore, the questions 9,10 and 11 of the second section of the questionnaire reflects the impressions and opinions of the participants under these circumstances." Also, it was suggested to students to reinforce the knowledge given in theoretical lectures with practical sessions using anatomy books, atlases, 3D anatomy resources for personal use, and YouTube videos, etc. To support theoretical and practical education, students were encouraged to use more online selected and recommended anatomy resources chosen by the department.

With the onset of the COVID-19 pandemic, both theoretical and practical anatomy knowledge was started to be evaluated in the same distance examination session by multiple-choice questions. These exams are conducted over the learning management system of the university. The fashion of practical exam was declared to the students just after the decision on distance education period. These exams are conducted on the learning management system of our university. For the practical part of the anatomy exam, a modified two-dimensional exam was conducted. Students are expected to identify an anatomical structure on the anatomical illustration and select the correct choice of the multiple-choice questions. Conventional and modified practical exam types were conducted before the pandemic in our department.

\section{Questionnaire development and data collection}

The first step of the preparation of questions of the section two and section three, was receiving the positive or negative verbal feedbacks of the student delegates before the research. These feedbacks were the origin and acted as a guide during the preparation of the questions. This feedback evolved into questions to the general student population and into a questionnaire to investigate the specific conditions of the students and the anatomy education process. The questions and the statements (propositions, Likert items) of the questionnaire were prepared by the authors (Table 1). The questionnaire was in Turkish. The second step is evaluating the evaluating the technical and statistical base of the questionnaire. In this step questionnaire designed not as a scale and set the points of the Likert-type questions, as well. The third step is the pilot application to test the questionnaire using a smaller sample size. Questions reviewed and revised based on the feedbacks of the pilot survey. During this process previous publications on the distant anatomy education are utilized $[2,3,8,20,27]$.

The students were informed about the questionnaire with a text explaining the purpose of the questionnaire, response time, the target audience, and the voluntariness of participation in the questionnaire. It was applied to medical students voluntarily. Questionnaire data were obtained between August and September 2020, just after the end of the term. Google Forms ${ }^{\circledR}$ was used to answer the questionnaire questions in the study. Thus, the data were obtained in the digital environment.

The questionnaire consists of three sections (Table 1). In the first section, general demographic information was requested. In the second section, the participants were asked to indicate their level of agreement with the statements presented. The questions in this section consist of five-point Likert-type questions that measure the participants' level of agreement in the propositions (Response options: Strongly disagree, Disagree, Neither agree nor disagree, Agree, Strongly Agree). In the first two sections, necessary technical adjustments were set up for the online questionnaire so that the participants asked to answer all the questions. In the third section, students' opinions were taken with open-ended questions. With the questions in the third section, the students were supported to express their opinions freely. Unlike the first two sections, replying in this section was optional.

\section{Quantitative data analysis}

The data set was exported from the Google Forms platform to Microsoft Excel (Microsoft Corp., Redmond, Washington, USA) and SPSS Statistics Standard Concurrent User V 25 (IBM Corp., Armonk, New York, USA) for organization, preparation, analysis, and visualization. Descriptive statistics (frequencies and percentages) were used to describe the obtained results. The Likert-item based independently evaluated Chi-square analysis method supported by the Monte Carlo simulation was used in evaluating the categorical data. The statistical significance level was determined as 0.05 . Cronbach's alpha was applied to measure the internal 
Table 1 Questionnaire form applied to evaluate the distance anatomy education and medical faculty student opinions during the COVID-19 pandemic (English translation of the questionnaire form)

Section-1 (S1)* (general information) Q1. Age

Q2. Gender

Q3. Semester (First year, Second year)

Q4. What do you think about the importance of anatomy courses in undergraduate education?

Q5. Have you ever had an experience of distance education before the COVID-19 pandemic?

Section-2 (S2)* (statements)

St1. Conducting theoretical anatomy lessons with video recordings (asynchronous) was more beneficial than face-to-face training

St2. Conducting theoretical anatomy lessons via online live class (synchronous) may be more beneficial than video recordings (asynchronous)

St3. Conducting theoretical anatomy lessons with video recordings (asynchronous) has been beneficial for my time management

St4. I had to more use of the anatomy resources (two or three dimensional) available on the web

St5. I had the opportunity to spend more time with anatomy textbooks

St6. According to my impression, theoretical anatomy lessons can be carried out via video recordings (asynchronous) during the formal education period

St7. According to my impression, the number of face-to-face anatomy lessons can be reduced by giving some of the theoretical lessons via video recordings (asynchronous) in anatomy education

St8. My opportunity to interact with the faculty member decreased during the distance education process

St9. According to my impression, three-dimensional digital resources can replace laboratory practice (model/cadaver) training

St10. The fact that the anatomy practice/laboratory courses were not carried out with the theoretical courses disrupted my education

St11. It was the right decision to include anatomy practice courses within the scope of distance education

St12. It was the right decision to include the anatomy theory exam within the online distance education/ exam scope

St13. It was the right decision to include the anatomy practice exam within the distance education/exam scope

St14. There has been no loss in terms of quality of anatomy education with the delivery of theoretical anatomy courses via distance education

St15. There has been no loss in terms of quality of anatomy education with the delivery of practical anatomy courses via distance education

Section-3 (S3)* (assessments)

Q1. What are your observations (deficiencies, suggestions, or ideas) about the distance anatomy education activities in this process?

Q2. What are your suggestions or opinions ideas for anatomy education methods after the COVID-19 pandemic?

*S section, $Q$ question, St statement

consistency between the items of the second section of the questionnaire.

\section{Qualitative data analysis}

The thematic qualitative content analysis method was preferred to evaluate the open-ended questions asked in the third section of the questionnaire [5]. It was planned to read the data several times by the researchers and to note the emerging themes in each participant's response. Thus, it was planned that each participant's answers to S3-Q1 and S3-Q2 would be included in one of the final themes that emerged during reading by authors.

\section{Results}

\section{Quantitative findings}

In this study, 402 students in the first and second years were reached to fill out the questionnaire voluntarily, and voluntary responses were received from 355 (88.3\%) of these students. The mean age of the participants in the study was 20.10 (SD: 1.30, Min: 18, Max: 29). The general demographic parameters of the participants are shown in Table 2. The participants' opinions in the first section about the importance of the anatomy course in undergraduate education (Table 1, S1-Q4) are presented in Table 3. The rate of students who had distance education experience (Table 1, S1-Q5) before the COVID-19 pandemic was $5.63 \%$. 
Table 2 Demographic parameters of the students (participants) according to their genders [Count (Row $N \%)$ ]

\begin{tabular}{lrrl}
\hline & \multicolumn{2}{l}{ Gender } & \\
\cline { 2 - 3 } Year & \multicolumn{1}{l}{ Male } & \multicolumn{1}{c}{ Female } & Total \\
\hline First-year students & $78(43.80)$ & $100(56.20)$ & $178(100)$ \\
Second-year students & $86(48.60)$ & $91(51.40)$ & $177(100)$ \\
Total & $164(46.20)$ & $191(53.80)$ & $355(100)$ \\
\hline
\end{tabular}

The results of the second section of the questionnaire are presented in Table 4 and Fig. 1. The value obtained by the associated Cronbach alpha was 0.711 . The statements in the second section can be summarized as follows according to the results of the statistical analysis: (St1) It is thought that giving the theoretical anatomy lessons face-to-face is more beneficial than video recordings (asynchronous) $(p=0.000)$. (St2) Synchronized theoretical anatomy lessons may be more beneficial than the asynchronous method $(p=0.043)$. (St3) It was stated that conducting the theoretical anatomy lessons using video records was beneficial in time management $(p=0.000)$. (St 4$)$ The students stated that they benefited more from the anatomy resources (two-dimensional or three-dimensional) available on the web $(p=0.000)$, and (St5) stated that they spend more time on anatomy textbooks $(p=0.000)$. (St6) The students emphasized that some of the theoretical anatomy lessons, not entirely, will be conducted through video recordings (asynchronous) during the formal education period $(p=0.000)$, (St7), thus the number of faceto-face anatomy lessons can be reduced $(p=0.000)$. (St8) The students stated that the interaction opportunities of the lecturer and the students decreased during the distance education process $(p=0.000)$. (St9) The students stated that three-dimensional digital resources could not replace laboratory practice training applied on models/cadavers $(p=0.000)$. (St10) The students stated that not carrying out anatomy practice/laboratory courses together with theoretical courses disrupted their education $(p=0.000),($ St11) emphasized that it was not the right decision to include anatomy practice courses in distance education $(p=0.000)$. (St12, St13) The students stated that they did not find it appropriate to conduct the anatomy practice exams as online

Table 3 Distribution of answers given to the question "What do you think about the importance of anatomy course in undergraduate education? (S1-Q4)" [Count (Row N\%)]

\begin{tabular}{|c|c|c|c|c|c|c|}
\hline Year & Not at all important & Slightly important & Important & Fairly important & Very important & Total \\
\hline First-year students & $0(0)$ & $3(1.69)$ & $9(5.06)$ & $52(29.21)$ & $114(64.04)$ & $178(100)$ \\
\hline Second-year students & $1(0.56)$ & $0(0)$ & $6(3.39)$ & $43(24.29)$ & $127(71.75)$ & 177 (100) \\
\hline Total & $1(0.28)$ & $3(0.85)$ & $15(4.23)$ & $95(26.76)$ & $241(67.89)$ & $355(100)$ \\
\hline
\end{tabular}

Table 4 Distribution of the answers given to the propositions (St1-St15) in the second part of the questionnaire (S2) $[n(\%)]^{*}$

\begin{tabular}{|c|c|c|c|c|c|c|c|}
\hline S2-Statements & $\begin{array}{l}\text { Strongly disa- } \\
\text { gree }(\%)\end{array}$ & Disagree (\%) & $\begin{array}{l}\text { Neither agree nor } \\
\text { disagree }(\%)\end{array}$ & Agree $(\%)$ & Strongly agree (\%) & Total (\%) & $\mathrm{p}^{* *}$ \\
\hline S2-St1 & $118(33)$ & $75(21)$ & $59(17)$ & $51(14)$ & $52(15)$ & $355(100)$ & 0.000 \\
\hline $\mathrm{S} 2-\mathrm{St} 2$ & $70(20)$ & $85(24)$ & $63(18)$ & $54(15)$ & $83(23)$ & $355(100)$ & 0.043 \\
\hline $\mathrm{S} 2-\mathrm{St} 3$ & $26(7)$ & $30(8)$ & $48(14)$ & $105(30)$ & $146(41)$ & $355(100)$ & 0.000 \\
\hline $\mathrm{S} 2-\mathrm{St} 4$ & $32(9)$ & $53(15)$ & $83(23)$ & $110(31)$ & $77(22)$ & $355(100)$ & 0.000 \\
\hline $\mathrm{S} 2-\mathrm{St} 5$ & $31(9)$ & $40(11)$ & $80(23)$ & $107(30)$ & $97(27)$ & $355(100)$ & 0.000 \\
\hline S2-St6 & $118(33)$ & $58(16)$ & $43(12)$ & $59(17)$ & $77(22)$ & $355(100)$ & 0.000 \\
\hline S2-St7 & $49(14)$ & $36(10)$ & $54(15)$ & $82(23)$ & $134(38)$ & $355(100)$ & 0.000 \\
\hline S2-St8 & $23(6)$ & $25(7)$ & $56(16)$ & $76(21)$ & $175(49)$ & $355(100)$ & 0.000 \\
\hline $\mathrm{S} 2-\mathrm{St} 9$ & $245(69)$ & $48(14)$ & $23(6)$ & $20(6)$ & $19(5)$ & $355(100)$ & 0.000 \\
\hline S2-St10 & $23(6)$ & $30(8)$ & $45(13)$ & $78(22)$ & $179(50)$ & $355(100)$ & 0.000 \\
\hline S2-St11 & $179(50)$ & $64(18)$ & $49(14)$ & $33(9)$ & $30(8)$ & $355(100)$ & 0.000 \\
\hline S2-St12 & $53(15)$ & $30(8)$ & 59 (17) & $75(21)$ & $138(39)$ & $355(100)$ & 0.000 \\
\hline $\mathrm{S} 2-\mathrm{St} 13$ & $144(41)$ & $58(16)$ & 49 (14) & $38(11)$ & 66 (19) & $355(100)$ & 0.000 \\
\hline S2-St14 & $88(25)$ & 66 (19) & $52(15)$ & 66 (19) & $83(23)$ & $355(100)$ & 0.018 \\
\hline S2-St15 & $219(62)$ & 66 (19) & $35(10)$ & $16(5)$ & $19(5)$ & $355(100)$ & 0.000 \\
\hline
\end{tabular}

* $S$ section, St statement

**Categorical data were evaluated independently, and the Chi-square analysis method supported by Monte Carlo simulation was used 


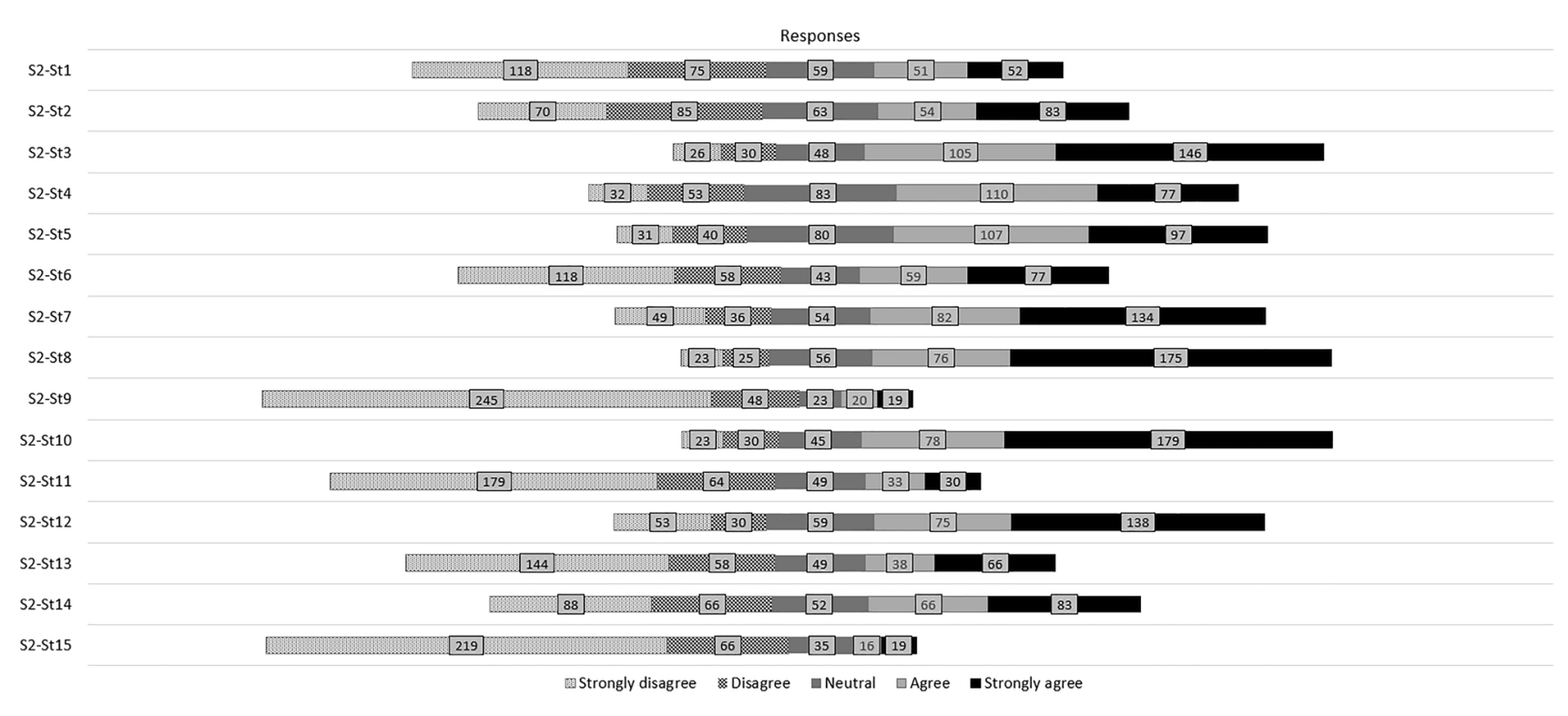

Fig. 1 Distribution of the answers given to the statements (St1-St15) in the second section (S2) of the questionnaire ( $n: 355)$

distance exams, but the opposite opinion for the theoretical anatomy exam $(p=0.000)$. (St14, St15) They stated that there was a loss in the quality of anatomy education, because theoretical $(p=0.018)$ and practical $(p=0.000)$ anatomy lessons were given by distance education.

\section{Qualitative findings}

The open-ended questions in the third section were evaluated by the researchers and categorized under themes qualitatively. The findings were summarized in Table 5 for S3-Q1 and Table 6 for S3-Q2. It was observed that answers in this section could also cover the topics that were asked for opinions in the questionnaire or that a participant could express an opinion on more than one theme. The rate of answering the open-ended questions in the third section was $34.08 \%$ (student count: 121) for S3-Q1 and 31.26\% (student count:
111) for $\mathrm{S} 3-\mathrm{Q} 2$. According to these answers, the total number of comments within the scope of 6 themes for S3-Q1 is 157 , and the total number of comments under four themes for S3-Q2 is 121 (Tables 5, 6).

For the question "What are your deficiencies, suggestions or ideas about the distance anatomy education activities in this process? (S3-Q1)", highest number of comments received regarding the theme "Negative aspects of practical anatomy education, which conducted distance education (anatomy education without cadaver)" (Table 5). For the question "What are your suggestions and ideas for anatomy education methods after the pandemic process? (S3-Q2)", highest number of comments received regarding the theme "Request for blended model (face-to-face practical sessions and distance theoretical lectures)" (Table 6).

Table 5 Distribution of the answers to the question "What are your deficiencies, suggestions or ideas about the distance anatomy education activities in this process? (S3-Q1)" according to the themes (Number of comments)

\begin{tabular}{|c|c|}
\hline Theme & $\begin{array}{l}\text { Com- } \\
\text { ment } \\
\text { Count }\end{array}$ \\
\hline 1. Satisfaction with the way the theoretical and laboratory lessons are given & 41 \\
\hline $\begin{array}{l}\text { 2. The positive effects of sharing theoretical lecture video recordings during the pandemic period, which were already recorded before } \\
\text { the pandemic }\end{array}$ & 5 \\
\hline 3. Satisfaction with the 3D anatomy atlas application, which was accessed in the distance education period & 11 \\
\hline 4. Negative aspects of practical anatomy education, which conducted distance education (anatomy education without cadaver) & 64 \\
\hline 5. Negative aspects of asynchronous theoretical lessons & 22 \\
\hline 6. Request for video recordings of lecture on cadaver and models & 14 \\
\hline Total & 157 \\
\hline
\end{tabular}


Table 6 Distribution of the answers to the question "What are your suggestions and ideas for anatomy education methods after the pandemic process? (S3-Q2)" according to the themes (Number of comments)

\begin{tabular}{ll}
\hline Theme & $\begin{array}{c}\text { Com- } \\
\text { ment } \\
\text { Count }\end{array}$ \\
\hline 1. Emphasizing the importance of the face-to-face education & 37 \\
2. Request for blended model (face-to-face practical sessions and distance theoretical lectures) & 55 \\
3. Request for increasing usage of three-dimensional educational resources & 4 \\
4. Request for make-up lessons for laboratories & 25 \\
Total & 121 \\
\hline
\end{tabular}

\section{Discussion}

The most critical reflection of the COVID-19 pandemic in the field of education was the interruption of face-to-face education. Institutions sought solutions to keep teaching their students by following the rules of physical distance [11]. Thanks to the opportunities brought by technology and the development of our understanding in educational sciences, distance education was a concept that the world had already met before [10]. However, the use of distance education, especially in areas, such as exams and practical education of health sciences, has been relatively limited due to the characteristics of this discipline based on the physical contact. Therefore, the educational institutions are trying to solve this problem using digital education methods. The continuation of both health education and examinations in the pandemic emerged as prominent issues that institutions had to face. At the beginning of the COVID-19 pandemic, there were not enough data in the literature to guide the medical educators in this area. In the first months of interruption of medical education, medical educators began producing similar solutions, although they could not make it clear how to face this problem [4].

With the pandemic, it has become necessary to introduce education models suitable for this process, especially in health education. The conditions caused by the COVID19 pandemic have created a testing environment, where no prior explicit scientific approval from educational scientists is required. The rapid transition toward unconventional education styles and resources in the field of health education was imperative [6]. In educational institutions that can quickly and healthily evaluate current conditions, the pandemic did not cause a complete interruption, at least in theoretical medical education. Under these conditions, both institutions, educators, and students are trying their best to manage the adaptation.

Solutions and new practical applications emerged in anatomy education as in all medical education fields in the pandemic. In the first period of the pandemic, anatomy education was given remotely in our country. Theoretical and practical lessons were carried out mostly live on digital platforms. Institutions evaluated conditions such as the number of students, the institution's physical facilities, the current and instant course of the pandemic throughout the country in terms of theoretical lessons, practical lessons, and exams. Due to the unique conditions of anatomy education, the reaction of anatomists had to be unique to them. While it was observed that theoretical courses and exams could be done remotely and anatomists did not find it difficult, conducting practical lessons and practical exams in given conditions seemed to be the biggest problem. Perhaps this process was an opportunity to discuss bringing a new dimension to anatomy education conducted within medical education regarding the applicability of distance education alternatives [13].

As an alternative method, distance education has been rapidly adopted in digital environments. However, it is still early to understand the educational impact of the partners of this process, especially on students. Today, medical students who take distance education have not yet entered the field and have not started to take a role in professional and academic environments [12]. The absolute results of the process we are still in will show themselves in many years. For this reason, investigating the perceptions and views of students and educators and operating feedback mechanisms may be the first opportunity to see the reflections of acute reactions at the institutional or educator level.

In this study, the medical faculty students' voluntary participation rate (88.30\%) to the applied questionnaire was evaluated as high. A digital online questionnaire method, which is now frequently used in many scientific disciplines, may affect this. We also think that the demand and need of students to provide feedback on the COVID-19 pandemic which forced them to a new learning environment, and demand to convey their ideas to the educators contributed to this high rate. The distribution of the demographic characteristics (gender and year of the education) of the participants was considered balanced.

According to the current study's findings: Most of our students stated that they had received formal distance anatomy education for the first time. The students found that face-to-face education more beneficial (St1). However, after the experience in this period, theoretical video lessons are found acceptable at a high level in the formal 
education period. Students stated that the number of faceto-face lessons can be reduced to a little, rather than that the theoretical lessons are entirely carried out through videos (St6 and St7). The interaction of the students with the lecturers seemed decreased (St8). Due to distance education, the students have better time management ( $\mathrm{St} 3$ ) and spend more time on supplementary resources (books, digital two- and three-dimensional resources) (St4 and St5). The students suggested that this study style will impact learning quality; however, they thought digital 3D resources could not replace cadavers. Although synchronous lessons were found statistically more beneficial (St2), this result may change when the statistical significance level is evaluated under the conditions, where a larger research population recruited, or extra factors were evaluated together. Participants thought that including anatomy education within the scope of distance education under the pandemic conditions disrupts anatomy education (St10 and St11). When the statistical significance level and the distribution of the answers are examined, it is observed that practical courses given by distance education cause a much higher quality loss than theoretical courses given by distance education (St14 and St15). For the statements St14 and St15 question, the preferred word "quality" is the standard of the satisfaction of learning anatomy when it is compared to unconventional conditions. The word "quality" represents the meaning of how good or how bad is. Even though it was not considered appropriate to conduct the practical exam remotely, it was considered the right decision to conduct the theoretical exam remotely ( $\mathrm{St} 12$ and St13).

The different features (socio-demographics, experience etc.) of the first- and second-year students may influence answers of the questionnaire. Separated evaluation may be required under these circumstances. We considered some of these features such as the experience based on the year of the studentship. As a preliminary analysis we statistically compared the answers of the first- and second-year students. According to the preliminary analyses we could not find remarkable differences between the first- and second-year students. Therefore, we decided to present the results without separating according to the year of the studentship.

Some studies and case reports on medical students' views on distance anatomy education in our country and worldwide have been published [22]. In some studies conducted in our country, it was determined that medical students were worried about not being physically present in the laboratory environment and they felt the lack of face-to-face theoretical anatomy education $[20,30,32]$. These results were found to be similar to our study findings.

Researchers reported findings consistent with and inconsistent with our study on medical school students with similar socio-demographic and academic characteristics [20, 30,
32]. Students' opinions such as distance anatomy education save students time and students are more active in learning have been identified as similar views revealed in our questionnaire. In addition, it has been reported that students stated that they were not satisfied with the theoretical and practical courses given by distance education [20, 30, 32]. Ortadeveci et al. [20] discussed the predictable advantages of traditional anatomy education. There was evidence in our study that students' opinions were positive about the hybrid system that was also proposed as a commentary by the Ortadeveci et al. [20] [Fig. 1, Table 4 (S2-St7) and Table 6 (S3-Q2, Theme 2)]. It has been determined that distance anatomy education can create different observations, experiences, and ideas for students in different learning environments shaped by students, lecturers, institutions' digital systems, and course resources. Our department offered video recordings of theoretical anatomy lessons to the students as a simultaneous alternative to face-to-face education during the two academic seasons before the pandemic. This may have contributed to the results reflecting more positive opinions regarding distance anatomy education in our questionnaire.

In the literature, parallel or divergent findings was also retrieved in several studies in which students' opinions from the faculty of medicine and dentistry in different countries were taken. Singal et al. [27] emphasized the importance of technical subjects for distance anatomy education and students' yearning for traditional anatomy education. In the study of Banovac et al. [2] the longing for peer education in the distance education process, in which online education cannot replace dissection and satisfaction with video lecture recordings, came to the fore. Hanafy et al. [14] detected negative perceptions about online preclinical education. Corte-Real et al. [7] stated that webinar-based education was observed as a better learning method. In the papers of Kim et al. [16] and Srinivasan [29] it is reported that the students were satisfied with the online courses, in the studies of Cuschieri, Calleja Agius [8] the students reported that they wanted recordings of the video lectures at the post-pandemic period. Yoo et al. [35] reported that distance education is preferred more than traditional education in their study. They attributed this conclusion to students' ability to use personal learning methods more, study more by themselves, and watch video lectures repeatedly.

We thought that the thematic evaluation of open-ended questions in our study is prominent compared to some other questionnaire studies that investigated students' opinions on the COVID-19 pandemic and distance anatomy education. Open-ended questions can also provide unpredictable views of the respondents during the researchers' design phase of the study. However, systematic evaluation of open-ended questions is a methodological problem. The thematic analysis offers some advantages for evaluating such open-ended questions [5]. The thematic categorization of the answers to 
the open-ended questions asked in the third section of the questionnaire is presented in Tables 5, 6. Among the themes in these tables, the demand for video lecture recordings on cadavers and models, the demand for make-up courses for laboratory lessons after the COVID-19 pandemic, and the demand for blended (face-to-face practical and distance theoretical) education prominent.

Nowadays, educational opportunities and resources of higher education institutions are diversified. The importance of digital foundation has been proven without hesitation in the COVID-19 pandemic process. The ability of medical schools' existing infrastructures to adapt to this sudden and challenging environment of transformation has provided that the initial responses in the COVID-19 pandemic environment were efficient and the transition was smooth. The digital education environment (such as LMS) must be transformable for distance education. Another critical issue is that the institutions' educational resources (library, model, cadaver, etc.) should be used without ethical and copyright problems in digital or distance education.

The engagement of the remote teaching module to institution's LMS, which was available before the pandemic, was provided by our university. According to this module design, theoretical and practical courses are divided into two as synchronous and asynchronous. Anatomy theoretical courses were carried out through synchronous and asynchronous courses. Anatomy practice lessons with cadavers and models were recommended to carry out as make-up lessons when returned to face-to-face education, according to the conditions of the COVID 19 process.

The students who participated in the questionnaire emphasized the importance of anatomy courses in medical education. This view was important, because our findings were the opinions of students with high awareness who believe in the high importance of the anatomy course. The students stated that they were satisfied with the digital recordings of the theoretical courses and that they found it useful in repeating and referencing the course. This feedback was considered a further highlight of a predicted and known result. As an educational project, our department has been recording anatomy lessons given in the classroom environment since the 2018-2019 academic year. These recordings were archived and published on a free platform that is restricted to our students and lecturers. [21]. When face-toface education was interrupted at the beginning of the pandemic, our previous course recordings and new recordings of the lessons taught online (synchronously or asynchronously) continued to be shared, which also contributed to the education of the students. In addition, the lack of video recordings of the models and cadavers in practical anatomy courses prepared by our faculty members was considered a weak aspect of the project.
Students were encouraged to use more online resources offered by our department to reinforce the theoretical and practical aspects of anatomy education. In this context, institutional free access for our students and lecturers was requested from the publisher of a 3D anatomy atlas, which declared its willingness to support anatomy education at the beginning of the pandemic. The participants reported their pleasure for this action (Table 5).

The COVID-19 pandemic has once again demonstrated how important educational digital investments and human resources are in distance education. In the upcoming period, universities should reconsider the distance education opportunities in undergraduate and graduate education and adapt to new technologic conditions. Especially, Z generation wishes to take advantage of this opportunity. In addition, $\mathrm{Z}$ generation seems to be a favorable generation for digital education and training [19]. The digital world seems to force us in many aspects of our education life and all areas of our lives.

In the coming years, it seems that some but not all the theoretical anatomy courses will be carried out through distance education (synchronous or asynchronous). This fashion of education may be more acceptable by the new generations. Our study findings indicated this demand with the items S2-St6 and S2-St7 of the questionnaire and the open-ended answers given to S3-Q2. In the future of distance education, the social media opportunities (YouTube Instagram, Twitter, etc.) that the digital world will offer us for the relations between the lecturers and the students will also be a new form of communication. The new generation of medical students seems prone to benefit more from the anatomy resources (two- or three-dimensional) available on the web. However, it is a fact that it is not correct to include anatomy practice/laboratory lessons within the scope of distance education unlike theoretical courses in the coming years. In our study, the students emphasized that anatomy education without contacting the cadaver would be undesirable. However, three-dimensional digital resources (models/ cadavers) should also reinforce the anatomy education.

\section{Limitations}

In this study, only the medical faculty students' opinions and the feedbacks about distance anatomy education conducted by our department in the pandemic period were discussed. All the positive and negative aspects of distance anatomy education or its place in whole medical education is not discussed. Our findings are based on observation and declaration. The factors that may impact the answers in the questionnaire could not be comprehensively controlled. National or international multi-center similar studies with students from different medical faculties may provide more comprehensive results. In this study, the effect of the COVID-19 
pandemic on factors such as students' success, social and economic status were excluded from research and analysis. In such studies, it may be possible to provide more detailed findings with advanced statistical analyses in which different issues may impact the questionnaire answers. This questionnaire was not planned as a scale study. In our opinion, this study will contribute to the formation of preliminary data for studies that can provide further analysis with more findings. As further research, correlational evaluation of the questionnaire answers and students' success may be conducted in future studies.

\section{Conclusion}

With the educational activities presented in this study, our students seem to be satisfied with the education we provide during the COVID-19 pandemic. The students reported no prominent problems in theoretical courses, but the lack of practical courses was felt. It is hoped that, by compiling experiences and suggestions, this study contributes to the examination of distant anatomy education during the COVID-19 pandemic, development of alternatives against similar situations in the future, to integrate into new educational models. As it is now clearly seen, hybrid methods in which video recordings of the lessons are included in the theoretical anatomy education process can be suggested to be added to face-to-face education. It would create the time and opportunities for the students to engage in a more accessible and interactive educational relationship with the anatomy educators. However, based on our study findings, we can state that the cadavers or models seem indispensable for our students for practical lessons.

Acknowledgements The authors have no conflicts of interest to declare. The authors did not receive funding from any organization for the submitted work.

Author contributions KEÖ: Project administration, Data collection, Formal analysis (Data analysis), Visualization, Writing-Original Draft. KE: Data collection, Writing-Review \& Editing. MAM: Project development, Conceptualization, Supervision, Writing-Review \& Editing.

\section{References}

1. Ahmed H, Allaf M, Elghazaly H (2020) COVID-19 and medical education. Lancet Infect Dis 20:777-778. https://doi.org/10.1016/ S1473-3099(20)30226-7

2. Banovac I, Katavic V, Blazevic A, Bicanic I, Hladnik A, Kovacic N, Petanjek Z (2021) The anatomy lesson of the SARSCoV-2 pandemic: irreplaceable tradition (cadaver work) and new didactics of digital technology. Croat Med J 62:173-186. https://doi.org/10.3325/cmj.2021.62.173
3. Baticulon RE, Sy JJ, Alberto NRI, Baron MBC, Mabulay REC, Rizada LGT, Tiu CJS, Clarion CA, Reyes JCB (2021) Barriers to online learning in the time of COVID-19: a national survey of medical students in the Philippines. Med Sci Educ 31:615-626. https://doi.org/10.1007/s40670-021-01231-z

4. Brassett C, Cosker T, Davies DC, Dockery P, Gillingwater TH, Lee TC, Milz S, Parson SH, Quondamatteo F, Wilkinson T (2020) COVID-19 and anatomy: stimulus and initial response. J Anat 237:393-403. https://doi.org/10.1111/joa.13274

5. Braun V, Clarke V (2006) Using thematic analysis in psychology. Qual Res Psychol 3:77-101. https://doi.org/10.1191/14780 88706qp063oa

6. Byrnes KG, Kiely PA, Dunne CP, McDermott KW, Coffey JC (2021) Communication, collaboration and contagion: "Virtualisation" of anatomy during COVID-19. Clin Anat 34:82-89. https://doi.org/10.1002/ca.23649

7. Corte-Real A, Nunes T, Caetano C, Almiro PA (2021) Cone beam computed tomography (CBCT) technology and learning outcomes in dental anatomy education: e-learning approach. Anat Sci Educ. https://doi.org/10.1002/ase.2066

8. Cuschieri S, Calleja Agius J (2020) Spotlight on the shift to remote anatomical teaching during COVID-19 pandemic: perspectives and experiences from the university of Malta. Anat Sci Educ 13:671-679. https://doi.org/10.1002/ase.2020

9. Das S, Al Mushaiqri M (2021) Anatomy online teaching during COVID-19 pandemic: the need for responsive anatomy learning ecosystem. Anat Sci Educ 14:428-429. https://doi.org/10.1002/ ase. 2082

10. Emanuel EJ (2020) The inevitable reimagining of medical education. JAMA 323:1127-1128. https://doi.org/10.1001/jama. 2020.1227

11. Evans DJR, Bay BH, Wilson TD, Smith CF, Lachman N, Pawlina W (2020) Going virtual to support anatomy education: a STOPGAP in the midst of the COVID-19 pandemic. Anat Sci Educ 13:279-283. https://doi.org/10.1002/ase.1963

12. Franchi T (2020) The impact of the COVID-19 pandemic on current anatomy education and future careers: a student's perspective. Anat Sci Educ 13:312-315. https://doi.org/10.1002/ ase. 1966

13. Gaur U, Majumder MAA, Sa B, Sarkar S, Williams A, Singh K (2020) Challenges and opportunities of preclinical medical education: COVID-19 crisis and beyond. SN Compr Clin Med 2:1992-1997. https://doi.org/10.1007/s42399-020-00528-1

14. Hanafy SM, Jumaa MI, Arafa MA (2021) A comparative study of online learning in response to the coronavirus disease 2019 pandemic versus conventional learning. Saudi Med J 42:324331. https://doi.org/10.15537/smj.2021.42.3.20200741

15. Hu B, Guo H, Zhou P, Shi ZL (2021) Characteristics of SARSCoV-2 and COVID-19. Nat Rev Microbiol 19:141-154. https:// doi.org/10.1038/s41579-020-00459-7

16. Kim JW, Myung SJ, Yoon HB, Moon SH, Ryu H, Yim JJ (2020) How medical education survives and evolves during COVID-19: our experience and future direction. PLoS ONE 15:e0243958. https://doi.org/10.1371/journal.pone.0243958

17. Longhurst GJ, Stone DM, Dulohery K, Scully D, Campbell T, Smith CF (2020) Strength, Weakness, Opportunity, Threat (SWOT) analysis of the adaptations to anatomical education in the United Kingdom and Republic of Ireland in response to the COVID-19 pandemic. Anat Sci Educ 13:301-311. https://doi. org/10.1002/ase.1967

18. Mahase E (2020) China coronavirus: WHO declares international emergency as death toll exceeds 200. BMJ 368:m408. https://doi. org/10.1136/bmj.m408

19. Marshall AL, Wolanskyj-Spinner A (2020) COVID-19: challenges and opportunities for educators and generation $\mathrm{Z}$ learners. Mayo 
Clin Proc 95:1135-1137. https://doi.org/10.1016/j.mayocp.2020. 04.015

20. Ortadeveci A, Ermez MN, Oz S, Ozden H (2021) A survey study on distance anatomy education: challenges unique to anatomy. Surg Radiol Anat. https://doi.org/10.1007/s00276-021-02772-z

21. Özen KE (2019) Evaluation of the contribution of video recordings of anatomy theoretical courses to anatomy education. In: Fulltext and Abstract book of The International Medical Congress of Izmir Democracy University, İzmir/Turkey, December 6-8, 2019. p 527

22. Öztürk Ş, Doğan NÜ, Ak A, Fazlığulları Z, Göktaş S (2021) Education experience of Selcuk University Faculty of Medicine during the COVID-19 pandemic. Tıp Eğitimi Dünyası 20:21-26. https://doi.org/10.25282/ted.768387

23. Patil NG, Chan Y, Yan H (2003) SARS and its effect on medical education in Hong Kong. Med Educ 37:1127-1128. https://doi. org/10.1046/j.1365-2923.2003.01723.x

24. Patra A, Ravi KS, Chaudhary P (2021) COVID 19 reflection/ experience on teaching-learning and assessment: story of anatomy teachers in India. Anat Sci Int 96:174-175. https://doi.org/ 10.1007/s12565-020-00576-6

25. Sahi PK, Mishra D, Singh T (2020) Medical education amid the COVID-19 pandemic. Indian Pediatr 57:652-657. https://doi.org/ $10.1007 / \mathrm{s} 13312-020-1894-7$

26. Sherbino J, Atzema C (2004) "SARS-Ed": severe acute respiratory syndrome and the impact on medical education. Ann Emerg Med 44:229-231. https://doi.org/10.1016/j.annemergmed.2004.05.021

27. Singal A, Bansal A, Chaudhary P, Singh H, Patra A (2021) Anatomy education of medical and dental students during COVID-19 pandemic: a reality check. Surg Radiol Anat 43:515-521. https:// doi.org/10.1007/s00276-020-02615-3

28. Spielman AI, Sunavala-Dossabhoy G (2021) Pandemics and education: a historical review. J Dent Educ. https://doi.org/10.1002/ jdd. 12615

29. Srinivasan DK (2020) Medical students' perceptions and an anatomy teacher's personal experience using an e-learning platform for tutorials during the COVID-19 crisis. Anat Sci Educ 13:318319. https://doi.org/10.1002/ase.1970

30. Şenol D, Toy Ş, Canbolat M, PektaŞ M (2020) Evaluation of online anatomy education given in medicine and dentistry faculties of universities during COVID-19 pandemic with student feedback. Konuralp Med J 13:30-35. https://doi.org/10.18521/ktd. 757819

31. Tucker RP, Anderson H (2021) Dissection experience and performance on a human gross anatomy written examination: lessons learned during the COVID-19 pandemic. Anat Sci Educ 14:169170. https://doi.org/10.1002/ase.2044

32. Turamanlar O, Güzel H (2021) The view of medical students on the anatomy course given by distance education during COVID-19 pandemic. Anatomy 14:202-209. https://doi.org/10.2399/ana.20. 820414

33. World Health Organization World Health Organization (2020) Coronavirus disease 2019 (COVID-19). Situation report-51. Geneva, Switzerland. https://www.who.int/docs/default-source/ coronaviruse/situation-reports/20200311-sitrep-51-COVID-19. pdf?sfvrsn=1ba62e57_10

34. World Health Organization. Country Statistics, The current COVID-19 situation. https://www.who.int/countries/tur/. Accessed August 2021

35. Yoo H, Kim D, Lee YM, Rhyu IJ (2021) Adaptations in anatomy education during COVID-19. J Korean Med Sci 36:e13. https:// doi.org/10.3346/jkms.2021.36.e13

Publisher's Note Springer Nature remains neutral with regard to jurisdictional claims in published maps and institutional affiliations. 